\title{
Awareness and Practices on Disaster Preparedness of Students of a Public High School in Antique
}

\author{
Gerry L. Ventura ${ }^{1}$ and Dennis V. Madrigal ${ }^{2}$ \\ ${ }^{1}$ Antique National School, Antique, Philippines \\ ${ }^{2}$ University of Negros Occidental-Recoletos, Bacolod City, Philippines
}

\begin{tabular}{l} 
Article history \\
Submitted: 22 October 2020 \\
Revised: 2 November 2020 \\
Accepted: 12 November 2020 \\
\hline Keywords: \\
Education \\
Management \\
Disaster Preparedness \\
Awareness \\
Practice \\
Descriptive-Correlational \\
Public High School \\
Antique
\end{tabular}

Introduction. Disasters cause deaths and serious disruptions in society, which call for the global community to take drastic steps to address and reduce the impacts of these inevitable calamities. That is why the government, through the Philippine Disaster Risk Reduction Management Act of 2010, requires the integration of disaster risk reduction in the school curriculum to strengthen the awareness and practice of personnel and students on calamity preparedness. Hence, the paper assessed the level of awareness and extent of practice on disaster preparedness before, during, and after the disaster of public junior high school students in Antique. Likewise, it sought to establish a difference in awareness and practice on disaster preparedness relative to sex, residence, and grade level and the relationship between awareness and practice.

Methods. Using a descriptive-comparative and correlational design, this paper assessed and correlate the awareness and practice on disaster preparedness among public junior high school students in Antique during 2019-2020. Employing researcher-made questionnaires for both awareness and practice, a total of 358 junior high school students, determined through stratified random sampling, responded in the study using these rating scales in Awareness: (1) Very poor, (2) poor, (3) moderate, (4) high, and (5) very high; Practice: (1) Very poor, (2) poor, (3) moderate, (4) great, and (5) very great. For the descriptive and inferential analyses of the data, Mean, Standard Deviation, Mann Whitney, Kruskal-Wallis, and Spearman Rank Correlation were utilized.

Results. As a whole, the findings revealed that the level of awareness on disaster preparedness of public students in Antique is high. Moreover, all periods were rated high. Meaning, these public students are aware of the necessity to prepare before, during, and after the disaster. Meanwhile, it was found out that among these periods, the students are highly aware during the disaster. In terms of demographics, females, students in non-prone areas, and Grade 10 are more aware of disaster preparedness than males, students in prone places, and other grade levels. The students are also highly aware of all disasters with the highest rating on the earthquake, which is a common drilled calamity in the school. On the one hand, the findings showed that the extent of practice on disaster preparedness of public students is great. This means that the students frequently practice preparedness before, during, and after the calamity. Correspondingly, female students in non-prone areas and Grades 7 and 10 have a greater extent of practice on disaster preparedness than their counterparts. It was also found out that students have a great extent of practice on all disasters with a high rating on earthquake. In terms of difference, the findings revealed a significant difference in students' awareness when grouped according to sex, residence, and grade level. Using the post hoc test, Grade 8 students have a lower level of awareness than other students. On the extent of the practice, there was a significant difference when Grade 8 students are grouped according to sex. At the same time, no difference was found when the residence was considered. Meanwhile, there were significant differences before, during, and after a disaster, when students were grouped according to grade level. Post hoc tests showed that Grade 8 students have a significantly lower extent of practice than other students. For the relationship, there was a significant relationship between awareness and practice. 
Conclusion. The high school students of a public high school in Antique demonstrate remarkable disaster preparedness awareness and practice before, during, and after natural disasters. Notwithstanding the areas of improvement, the public school has positively instilled among students the importance of being prepared for disasters to prevent, mitigate, respond to, and recover from its devastating effects on human lives and the environment. In addition, the correlation between awareness and practice of disaster preparedness denotes the critical role that education plays in making students disaster resilient in school and at home. Hence, school personnel may take advantage of school activities as avenues for raising awareness and forming students' attitudes regarding disaster preparedness.

Practical Value of the Paper. The study contributes to the dearth of literature on disaster preparedness in public schools. This may also provide thorough information for administrators to prepare, mitigate, respond to, and recover effectively from the impacts of imminent hazards that may occur within schools. This will also aid teachers in incorporating disaster preparedness in the curriculum to prepare students before, during, and after disasters. Furthermore, the paper encourages future researchers to explore studies on preparedness for man-made disasters and other variables that were not covered by the study.

\section{References}

Alcayna, T., Bollettino, V., Dy, P., \& Vinck, P. (2016). Resilience and disaster trends in the Philippines: opportunities for national and local capacity building. PLoScurrents, 8.

Andrino, R. M., Cabigon, M. T. T., Geocadin, K. P., Laja, C. J. G., \& Pilar, J. G. A. (2016). Evacuation Mapping Plan of Disaster Management and Response. Virtutis Incunabula, 3(1).

Bhebhe, S., Runhare, T., \& Monobe, R. J. (2019). Strategic approaches for developing a culture of safety management in schools: Indications from literature studies. Jàmbá: Journal of Disaster Risk Studies, 11(2).

Blanco, D. V. (2015). Disaster governance in the Philippines: Issues, lessons learned, and future directions in the postYolanda super typhoon aftermath. International Journal of Public Administration, 38(10), 743-756.

Maminta, L. G. (2019, November). Level of Awareness on Disaster Preparedness. In Journal of Physics: Conference Series (Vol. 1254, No. 1, p. 012015). IOP Publishing.

Marpa, E. P., Juele, M., \& Hiyas, R. (2016). Environmental awareness and practices among high school students: Basis for disaster preparedness program. In Applied Mechanics and Materials (Vol. 848, pp. 240-243). Trans Tech Publications Ltd.

Padernal, P. O., \& Borja, E. A. (2016). Disaster Risk Reduction Awareness Among Junior High School Students of Surigao City. Proceedings Journal of Education, Psychology and Social Science Research, 3(02).

Tyas, R. A. (2020, January). Students Perception Toward Their Preparedness for Volcanic Eruption Disaster. In Journal of Physics: Conference Series (Vol. 1440, No. 1, p. 012086). IOP Publishing.

Valenzuela, V. P. B., Esteban, M., Takagi, H., Thao, N. D., \& Onuki, M. (2020). Disaster awareness in three low-risk coastal communities in Puerto Princesa City, Palawan, Philippines. International Journal of Disaster Risk Reduction, 46, 101508.

Yuliana, Y., Sulastri, S., \& Nasaruddin, N. (2019). Analysis of the Level of Resilience of Post Disaster Earthquake State High School Students in Pidie Jaya District. International Journal of Multicultural and Multireligious Understanding, 6(2), 636-643.

\section{Correspondence:}

Gerry L. Ventura [gerryum7@gmail.com]

https://orcid.org/0000-0001-7572-3658 